\title{
Fractura de estrés en meseta tibial medial
}

\author{
Medial tibial plateau stress fracture \\ Luis Gerardo Domínguez Gasca, ${ }^{*}$ Jorge Magaña Reyes, ${ }^{\ddagger}$ Luis Gerardo Domínguez Carrillo§
}

Hombre de 58 años, sin antecedentes de importancia, quien, durante los últimos 10 años, realizaba caminata de siete kilómetros diarios. En la última semana, inició con alternancia de un kilómetro de trote por 250 metros de carrera, presentando en la última sesión dolor en la cara medial de la rodilla derecha, debido a que resbaló y la giró bruscamente sin colisionar con el piso. A la exploración física, se encontró: marcha claudicante a expensas de extremidad pélvica derecha en semiflexión, discreto edema en cara medial de la misma, dolor a la presión de la línea interarticular medial, al igual que a la digitopercusión sobre la inserción del tendón de la pata de ganso; los arcos de movimiento articular de rodilla se encontraron completos; las pruebas de cajón, de Lachman, de estrés en valgo y varo resultaron negativas; las pruebas de Apley, McMurray y de O'Donoghue fueron positivas para menisco medial.

Debido al corto tiempo de la lesión se consideraron las posibilidades diagnósticas de: a) lesión de menisco medial (por el mecanismo giratorio de la rodilla); b) fractura de estrés en metáfisis de la tibia (por el tipo y el tiempo de ejercicio efectuado con cambios de velocidad e intensidad en la última semana); c) tendinitis y bursitis anserina (por el mecanismo de lesión). Por lo anterior, se decidió efectuar una resonancia magnética, la cual mostró fractura de estrés
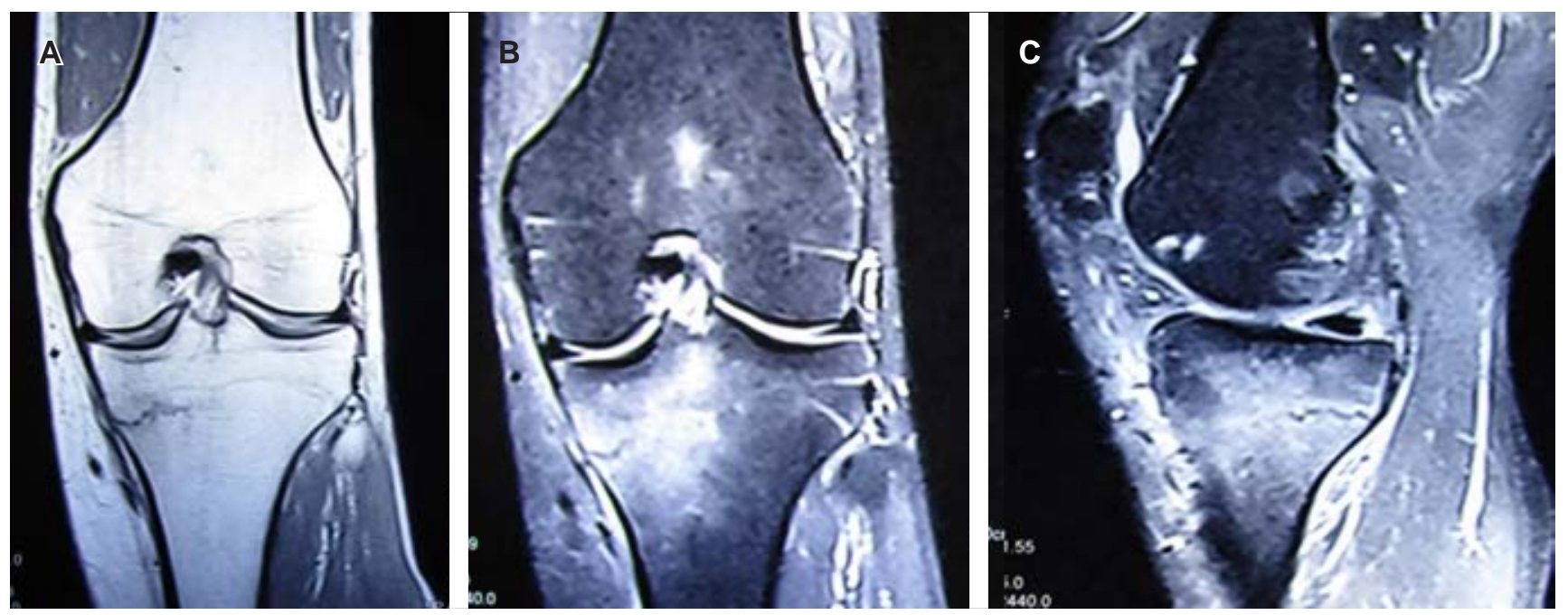

Figura 1: Imágenes de resonancia magnética: (A) ponderada en T1 en plano coronal, mostrando fractura metafisiaria, abarcando 40\% del platillo tibial medial; (B) plano coronal en T2 con supresión grasa, mostrando edema óseo en $50 \%$ de la porción medial de la metáfisis de la tibia; (C) corte sagital, edema óseo y fractura metafisiaria de tibia derecha sobre vertiente posterior.

\footnotetext{
* Ortopedista. División de Cirugía.

* Radiólogo. Departamento de Imagenología.

$\S$ Medicina de Rehabilitación. División de Medicina.
}

Hospital Ángeles León, León, Guanajuato. México.
Correspondencia:
Dr. Luis Gerardo Domínguez Carrillo
Correo electrónico: Igdominguez@hotmail.com
Aceptado: 08-03-2019. 
metafisaria de la tibia, no desplazada, que abarcaba el $40 \%$ de ésta (Figura 1).

Las fracturas por estrés de la extremidad inferior ocurren comúnmente en atletas y militares. El eje tibial es el lugar más común para las fracturas por estrés durante las actividades de carrera y marcha, mientras que la meseta tibial medial es un sitio relativamente poco frecuente; siendo difícil de detectar en las radiografías iniciales al inicio de los síntomas. Esta lesión es fácilmente diagnosticada de manera errónea, debido a que la ubicación del dolor y la sensibilidad es muy similar a la lesión meniscal medial y a la bursitis anserina. Wang y su equipo ${ }^{1}$ mencionan que la mecánica dinámica de contacto de la meseta tibial y la porción posterior soportan presiones de contacto pico más altas que la porción anterior en la fase de apoyo entre el 14 y $18 \%$ del ciclo de la marcha, alcanzando cargas axiales de 2280 newtons. Esto resulta consistente al hecho de que la ubicación más frecuente de las fracturas por estrés en la meseta tibial medial es en la vertiente posterior, como en el caso presentado.
La gammagrafía ósea, la tomografía computarizada (TC) y la resonancia magnética (RMN) se usan para la detección temprana de las fracturas por estrés, ${ }^{2}$ siendo la resonancia magnética más sensible que la tomografía computarizada y más específica que la gammagrafía, ya que ésta es útil para detectar el edema del hueso esponjoso, que generalmente se presenta como una línea de fractura lineal en la meseta tibial medial. ${ }^{3}$

\section{REFERENCIAS}

1. Wang $\mathrm{H}$, Chen T, Torzilli P, Warren R, Maher S. Dynamic contact stress patterns on the tibial plateaus during simulated gait: a novel application of normalized cross correlation. J Biomech. 2014; 47 (2): 568-574.

2. Gaeta M, Minutoli F, Scribano E, Ascenti G, Vinci S, Bruschetta D et al. CT and MR imaging findings in athletes with early tibial stress injuries: comparison with bone scintigraphy findings and emphasis on cortical abnormalities. Radiology. 2005; 235 (2): 553-561.

3. Yukata K, Yamanaka I, Ueda Y, Nakai S, Ogasa H, Oishi Y et al. Medial tibial plateau morphology and stress fracture location: a magnetic resonance imaging study. World J Orthop. 2017; 8 (6): 484-490. 